\title{
水分胁迫对水稻籽粒蛋白质积累及营养品质的影响
}

\author{
蔡一霞 ${ }^{2}$ 王 维 ${ }^{2}$ 朱庆森 $^{1 *}$ \\ （1 扬州大学，江苏省作物遗传生理重点实验室 江苏扬州 225009) \\ (2 华南农业大学农学院,广州 510642)
}

摘 要 以生产上广泛使用的水稻( Oryza sativa) 品种 汕优 63' ‘扬稻 6 号' 和 武育粳 3 号' 为材料, 研究了水分胁 迫对结实期水稻籽粒蛋白质积累及营养品质的影响。结果表明 :正常施氮水平下，花后 $10 \sim 20 \mathrm{~d}$ 的水分胁迫提高 了谷氨酰胺合成酶(Glutamine synthetase, GS)和谷氨酸合酶 (Glutamate synthase,GOGAT)活性 ,提高了籽粒自身利用无 机氮合成氨基酸的能力，从而利于籽粒内蛋白质的积累，而高氮水平下，水分胁迫降低了籽粒自身合成氨基酸的能 力。以重量为基数的蛋白质含有率在整个灌浆过程中呈 V”型消长, 正常施氮水平下, 水分胁迫明显提高了花后 15 $\mathrm{d}$ 至成熟期蛋白质含有率, 而高氮水平下, 水分胁迫处理的蛋白质含有率明显低于水层灌溉。与水层灌溉相比, 水 分胁迫提高了正常施氮水平下精米中醇溶蛋白和谷蛋白含量, 但却明显降低了高氮水平下精米中醇溶蛋白和谷蛋 白含量。水分胁迫对稻米中赖氨酸含量的影响因品种、植株的氮营养水平的不同而不同，水分胁迫显著降低了两 种氮肥水平下 汕优 $63^{\prime}$ 中赖氨酸含量，但却明显提高 扬稻 6 号' 中赖氨酸含量 ;而 武育粳 3 号' 于两种氮肥水平 下表现恰好相反 , 正常施氮水平下赖氨酸含量略有升高; 而高氮水平下赖氨酸含量明显降低。

关键词 水分胁迫 蛋白质积累 赖氨酸 水稻

\section{EFFECTS OF WATER STRESS ON NUTRIENT QUALITY AND ACCUMULATION OF PROTEIN IN RICE GRAINS}

\author{
CAI Yi-Xia ${ }^{12}$, WANG Wei ${ }^{2}$, and ZHU Qing-Sen ${ }^{1 *}$ \\ ${ }^{1}$ Key Laboratory of Crop Genetics and Physiology, Yangzhou University , Yangzhou , Jiangsu 225009 , China , and ${ }^{2}$ College of Agronomy , South \\ China Agricultural University , Guangzhou 510642 , China
}

\begin{abstract}
Aims Soil drying is an important factor threatening rice production in China , and there has been much recent research on the development of grain yield and quality in rice grown under shortages of water. The objective of this study is to examine the effects of soil moisture and $\mathrm{N}$ supply levels on rice grain $\mathrm{N}$ accumulation and nutrient quality.
\end{abstract}

Methods We conducted a pot study using three rice cultivars and varying in N content to examine physiological characteristics for $\mathrm{N}$ accumulation and distribution to grains during the grain-filling period in response to water stress and $\mathrm{N}$ supply exposure at heading stage.

Important findings The activities of glutamine synthetase (GS) and glutamate synthase (GOGAT) involved in $\mathrm{N}$ metabolism were enhanced by mild water stress at 10-20 DAA (days after anthesis) under normal $\mathrm{N} \mathrm{lev-}$ $\mathrm{el}$, and abilities to synthesize amino acids were improved, which promoted the accumulation of $\mathrm{N}$ and elevated the protein content in grains. However, the activities of GS and GOGAT were negatively affected by mild water stress with exposure to high $\mathrm{N}$ level, which resulted in decreased synthesis of amino acids. The dynamic changes of the ratio of protein to grain weight presented a " V" type during grain-filling. Water stress improved the ratio of protein to grain weight from $15 \mathrm{DAA}$ to harvest under normal $\mathrm{N}$ level, but the ratio was decreased by water stress under higher $\mathrm{N}$ level when compared with well-watered treatments. Changes of four component parts of protein subjected to water stress varied with nitrogen levels and cultivars. Compared to well-watered treatment , the water-stressed treatment had higher contents of prolamine and glutelin under normal $\mathrm{N}$ level , but the contents of prolamine and glutelin subjected to water stress were significantly less than those in the well-watered treatment under higher $\mathrm{N}$ level. Water stress affected the lysine content of grains, and varied with cultivars and N supplies. Lysine contents of Shanyou63' under two N levels were decreased by water stress, but 
were increased in 'Yangdao6' . The variation observed in enzymes involved in $\mathrm{N}$ metabolism and partitioning at grain filling to grains of the rice imposed by water stress at heading indicated that plant genotypes influence $\mathrm{N}$ accumulation and protein components of grains and subsequent nutrient quality.

Key words water stress, accumulation of protein, lysine , Oryza sativa

碳、氮代谢是植物体内最基本的两大代谢过程， 籽粒内碳、氮化合物的合成、积累与其产量、品质有 着密切联系 (Lawlor, 2002)。淀粉和蛋白质是水稻 (Oryza sativa) 籽粒中两大内含物, 其中淀粉占精米 的 $90 \%$, 蛋白质占精米的 6\% 8\% , 并且这两种内 含物含量的多少、生理生化特性决定着稻米品质和 米饭的食味及米饭的质地 (Evers \& Millart, 2002)。 由于淀粉所占的比率大, 有关稻米品质的研究多集 中在籽粒内淀粉的数量和质量及其与品质关系、以 及环境条件、栽培措施等对其的影响 (黄发松等, 1998）,但近年来许多研究者发现, 水稻蛋白质的数 量及各组分对稻米食味品质的影响极大 (Okadome et al ., 1999 ; Martin \& Fitzgerald , 2002) , 且因稻米继 续保持其主食地位, 其营养问题也很重要 (朱智伟 等, 1991 ; 卢良恕，1990)。稻米的营养品质主要是 指蛋白质和赖氨酸含量, 稻米蛋白质含量虽低, 但其 生物价和蛋白价均高于小麦和玉米，在植物性蛋白 中具有显著的优越性, 因此有许多研究者致力于高 蛋白的水稻育种和栽培(Dunn et al , 2000)。土壤 水分作为影响水稻生长发育的重要环境因子, 有关 其与水稻籽粒中蛋白质代谢及其营养品质的关系， 目前还未见报道。本文以生产上广泛应用的品种为 材料, 于始穗期始设置两种氮肥水平, 于齐穗期起进 行适度水分胁迫处理 $(-30 \mathrm{kPa})$, 分析了籽粒形成 过程中谷氨酰胺合成酶 (Glutamine synthetase, GS) 和 谷氨酸合酶 (Glutamate synthase, GOGAT) 活性动态变 化以及籽粒中蛋白质积累的变化动态, 探讨水分胁 迫下稻米营养品质, 为生产上通过合理的水肥措施 来调控稻米蛋白质合成和积累提供理论依据。

\section{1 材料和方法}

\section{1 试验设计}

试验于 2003 年在扬州大学江苏省作物栽培生 理重点实验室盆栽试验场实施, 供试品种为 汕优 63 ' ‘扬稻 6 号' 和 武育粳 3 号'。用 $20 \mathrm{~cm}$ (底 径 $) \times 30 \mathrm{~cm}$ (口径 $) \times 30 \mathrm{~cm}$ (高) 的白色塑料盆进行 盆栽,每盆装 $18 \mathrm{~kg}$ 过篮的耕作层土壤(砂壤土) , 土 取自前茬小麦地。每盆施基肥 $2 \mathrm{~g}$ 尿素和 $1 \mathrm{~g}$ 磷酸 氢二钾; 保花肥 $1 \mathrm{~g}$ 尿素, 抽穗前的管理与大面积生
产一致。自始穗期设置正常施氮 (每盆 $0.5 \mathrm{~g}$ 纯氮, $\mathrm{NN}$ ) 和高氮 (每盆 $2 \mathrm{~g}$ 纯氮, $\mathrm{HN}$ )两种水平, 以尿素作 为氮源, 于齐穗期设置浅水层 $(0 \mathrm{kPa}, \mathrm{WW})$ 和轻度 水分胁迫 $(-30 \mathrm{kPa}, \mathrm{WS})$ 两种水分处理, 每个处理 20 盆, 共 240 盆。下雨时用塑料膜拱棚遮雨, 天晴 时撤除。用土壤水分张力计 (中国科学院南京土壤 研究所生产, 每盆 1 支)监测土壤水分, 每天 7:00 $8: 00$ 和 $11: 00 \sim 12: 00$ 分别记录土壤水势值 1 次, 以 两次的平均值代表当日的盆土壤水势, 若低于处理 所设定的土壤水势, 则根据经验浇一定量的水, 使张 力计读数达到所设定土壤水势。

\section{2 测定内容与方法}

\subsection{1 抽穗期挂牌与取样}

抽穗期选取同日开花、生长一致的单茎挂牌，于 花后每隔 $5 \mathrm{~d}$ 取样 1 次, 每次取 16 穗, 分成 2 份, 每 份 8 穗,一份于液氮中固定 $15 \mathrm{~min}$, 冰箱中保存, 用 于酶活性测定; 另一份将籽粒取下, 称鲜重, 置烘箱 中 $105{ }^{\circ} \mathrm{C}$ 杀青 $0.5 \mathrm{~h}$,于 $80{ }^{\circ} \mathrm{C}$ 烘干至恒重 称重。

\subsection{2 籽粒中 GS 和 GOGAT 活性的测定}

取去壳水稻籽粒 25 粒, 称重, 用 $5 \mathrm{ml} 0.1 \mathrm{~mol}$ $\mathrm{L}^{-1}$ Tris-HCl $\left(\mathrm{pH}\right.$ 值为 7.5) 缓冲液 (内含 $5 \mathrm{mmol} \mathrm{\textrm {L } ^ { - 1 }}$ 2-mercaptoethanol 和 $2 \mathrm{mmol} \mathrm{\textrm {L } ^ { - 1 }}$ EDTA) 研磨成均浆, 以 $20000 \mathrm{~g} \mathrm{~min}^{-1}$ 速度于 $4{ }^{\circ} \mathrm{C}$ 离心 $10 \mathrm{~min}$, 上清液即 为粗酶液 酶反应的温度为 $30{ }^{\circ} \mathrm{C}$, 具体方法如下:

$\mathrm{GS}$ : 将 $0.5 \mathrm{ml}$ 的反应液 (内含 $100 \mathrm{mmol} \mathrm{L} \mathrm{L}^{-1} \mathrm{im}-$ idazole-HCl ( $\mathrm{pH}$ 值为 7.2)、20 mmol $\mathrm{L}^{-1} \mathrm{MgCl}_{2} 、 25$ mmol $\mathrm{L}^{-1}$ 2-mercaptoethanol、 $50 \mathrm{mmol} \mathrm{L}^{-1}$ sodium Lglutamate $\left(\mathrm{pH}\right.$ 值为 7.2)、125 mmol $\mathrm{L}^{-1}$ Hydroxylamine ( $\mathrm{pH}$ 值为 7.2) 和 $10 \mathrm{mmol} \mathrm{L}{ }^{-1}$ ATP) 加入 $100 \mu \mathrm{l}$ 的粗 酶液中, 于 $30{ }^{\circ} \mathrm{C}$ 的水浴中保温 $15 \mathrm{~min}$, 再加入 0.75

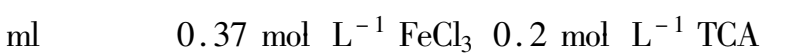
$\left.0.67 \mathrm{~mol} \mathrm{~L}{ }^{-1} \mathrm{HCl}\right)$ 终止反应, 于 $535 \mathrm{~nm}$ 处读取吸光 度。以不含 ATP 和 glutamate 的反应液为对照。酶 活性的单位定义为: 以 $30{ }^{\circ} \mathrm{C}$ 每 $1 \mathrm{~h}$ 反应液 $\Delta \mathrm{OD}_{535}$ 等 于 0.01 为 1 个酶活性单位, 最后依据样品籽粒数和 稀释倍数计算酶的活性, 单位为 unit grain ${ }^{-1} \mathrm{~h}^{-1}$ 。

GOGAT: 在 $1 \mathrm{ml}$ 的反应液 (内含 $0.1 \mathrm{~mol} \mathrm{~L}^{-1}$

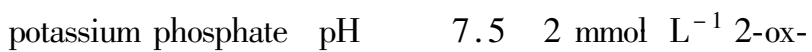

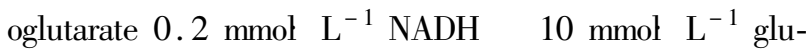


tamine)中加入 $100 \mu \mathrm{l}$ 的粗酶液, 于 $30{ }^{\circ} \mathrm{C}$ 的水浴中保 温 $30 \mathrm{~min}$ 后, 于沸水中杀死酶活性 $30 \mathrm{~s}$, 于 $340 \mathrm{~nm}$ 处读取吸光度, 以不含 glutamine 的反应液为对照。 酶活性用氧化的 NADH 量 (以 $\mathrm{OD}_{340}$ 值减少量表示) 来计算 GOGAT 的活力, 以 $30{ }^{\circ} \mathrm{C}$ 每 $1 \mathrm{~h}$ 减少 $\Delta \mathrm{OD}_{340}$ 等于 0.01 为 1 个酶活性单位, 最后依据样品籽粒数 和稀释倍数计算酶的活性, 单位为 unit grain $^{-1}$. $\mathrm{h}^{-1}$ 。

\section{2 .3 蛋白质积累动态及成熟期籽粒中蛋白质组} 分的测定

将 1.2.1 中烘干的籽粒, 剥去谷壳, 磨成粉, 过 100 目篮，用凯氏定氮法测定籽粒含氮率，含氮率乘 以系数 5.95 即为以籽粒干重为基数的蛋白质含有 率, 单粒为基数的蛋白质绝对含量 $=$ 蛋白质含有 率 $\times$ 单粒籽粒重。

蛋白组分的分离采用陈毓荃 (1995) 文献中的谷 物种子蛋白质的分级分离, 用水、 $10 \% \mathrm{NaCl} 、 75 \%$ 乙 醇和 $0.2 \% \mathrm{NaOH}$ 溶液作溶剂，分别提取清蛋白、球 蛋白、醇溶蛋白及谷蛋白 4 种不同组分, 加浓硫酸 , $\mathrm{H}_{2} \mathrm{O}_{2}$ 作催化剂, 消煮, 并用邹琦 (2000) 文献中的纳 氏比色法定量。

\subsection{4 精米中粗蛋白和赖氨酸含量的测定}

精米中粗蛋白是用 FOSS TECTOR 公司生产的 近红外分析仪 1241 分析测定。

赖氨酸测定主要参照李合生 (1999) 文献谷类作 物种子中赖氨酸含量的测定, 并略作修改, 具体方法 如下: 准确称取经石油醚 (沸程 $60 \sim 90{ }^{\circ} \mathrm{C}$ ) 脱脂的精 米粉 $25 \mathrm{mg}$, 放入预先烘干的试管中，加 $1 \mathrm{ml} 2 \%$ 的 碳酸钠溶液, 于旋涡振荡器上旋 $10 \mathrm{~min}$, 然后将试管 放入 $80{ }^{\circ} \mathrm{C}$ 恒温水浴中，其间将试管取出于旋涡振荡 器上混匀, 保温提取 $10 \mathrm{~min}$ 。取出试管, 向每管内加 入 $2 \mathrm{ml}$ 狮三酮试剂(称取 $1 \mathrm{~g}$ 狮三酮和 $1 \mathrm{~g}$ 氯化镉 $\left(\begin{array}{lll}\mathrm{CdCl}_{2} & \mathrm{H}_{2} \mathrm{O}\end{array}\right)$ ), 加入 $25 \mathrm{ml}$ 甲酸钠缓冲液 (称取 $30 \mathrm{~g}$ 甲酸钠, 溶解于约 $60 \mathrm{ml}$ 蒸馏水中, 加入 $10 \mathrm{ml} 8 \%$ 的 甲酸, 最后加水定容至 $100 \mathrm{ml}$ ) 和 $75 \mathrm{ml}$ 乙二醇, 室温 下放置 $1 \mathrm{~d}$ 第二天使用) ,混匀, 于 $80{ }^{\circ} \mathrm{C}$ 恒温水浴中 保温显色 $30 \mathrm{~min}$, 同时以蒸馏水做一空白对照, 取出 后, 于冷水中冷却 $3 \mathrm{~min}$, 加 $5 \mathrm{ml} 95 \%$ 乙醇, 混匀, 过 滤, 于 $500 \mathrm{~nm}$ 处读取吸光度。若样品颜色过深, 可 吸取一定量的样品反应液用 $95 \%$ 乙醇稀释后比色。 标准曲线的配制, 准确称取 $250 \mathrm{mg}$ 亮氨酸, 加数滴 稀盐酸, 待溶解后定容至 $500 \mathrm{ml}$, 该溶液亮氨酸的浓 度为 $500 \mu \mathrm{g} \mathrm{mL} \mathrm{m}^{-1}$,从上述母液中吸取 2、6、10、14、18 $\mathrm{ml}$ 分别稀释至 $50 \mathrm{ml}$,形成 $20 、 60 、 100 、 140 、 180 \mu \mathrm{g}$ $\mathrm{mL}^{-1}$ 系列的标准浓度。吸取上述标准系列浓度的 溶液 $0.5 \mathrm{ml}$ 于试管中 (以 $0.5 \mathrm{ml}$ 蒸馏水作空白) ,加 入 $0.5 \mathrm{ml} 4 \%$ 碳酸钠溶液和 $2 \mathrm{ml}$ 狮三酮试剂, 混匀, 于 $80{ }^{\circ} \mathrm{C}$ 恒温水浴上保温 $30 \mathrm{~min}$, 取出后立即冷却 3

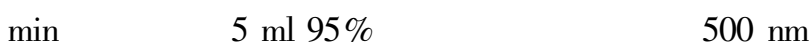
处读取吸光度。

\section{2 结果与分析}

\section{1 水分胁迫对籽粒中 GS 和 GOGAT 活性的影响}

由图 1 可以看出，结实期 GS 和 GOGAT 活性变 化因品种类型和水肥措施的不同表现出明显的差 异 三系杂交籼稻 汕优 63' 和常规籼稻 扬稻 6 号' 两品种 GS 和 GAGOT 活性变化的趋势基本一致, 而 武育粳 3 号’ 与前两者有所不同。

GS :在正常施氮水平下', 汕优 63’ 和 扬稻 6 号' GS 活性于花后 $10 \mathrm{~d}$ 达到最大, 其后迅速下降, 花 后 $20 \mathrm{~d}$ 至成熟期酶活性变化幅度较小, 在花后 10 $15 \mathrm{~d}$ 水分胁迫下籽粒中 GS 活性有所增加; 而在高氮 水平下', 汕优 $63^{\prime}$ 和 扬稻 6 号' GS 活性于花后 $15 \mathrm{~d}$ 才达到峰值，其后迅速下降，水分胁迫使得 $10 \sim 15 \mathrm{~d}$ 的酶活性明显降低。“武育粳 3 号'在开花初期(花 后 5 15 d) 酶活性增加较慢, 在 $15 \sim 25 \mathrm{~d}$ 酶活性维 持在一个较高的水平上, 然后才开始缓慢降低; 正常 施氮水平下, 水分胁迫使 武育粳 3 号' 花后 $10 \sim 20$ $\mathrm{d}$ 的 GS 酶活性略有提高, 而高氮水平下, 水分胁迫 使酶活性的表达受到抑制，花后 10～25d GS 活性明 显低于水层灌溉的。同时可以看出, 结实期增施氮 肥有利于 GS 活性的增加, 促进氨同化作用。

GOGAT :在灌浆前期（花后 5d）,同一氮肥水平 下 汕优 $63^{\prime}$ 和 扬稻 6 号' 两品种水分胁迫处理的 GOGAT 活性明显低于水层灌溉处理, 高氮水平使该 酶活性迅速升高, 于花后 $10 \mathrm{~d}$ 就达到峰值, 而在正 常施氮水平下, 酶活性增加较慢, 到花后 $15 \mathrm{~d}$ 才达 到峰值, 其后酶活性迅速下降; 两种氮肥水平下武 育粳 3 号' GOGAT 活性均于花后 $15 \mathrm{~d}$ 达到峰值, 水 分胁迫下明显提高了 GOGAT 活性峰值, 但在花后 $15 \sim 20 \mathrm{~d}$, 水分胁迫处理的酶活性降幅较大, 明显小 于水层灌溉。

\section{2 水分胁迫对籽粒内蛋白质积累的影响}

籽粒灌浆结实期间，以籽粒干重为基数的蛋白 质含有率的变化和以单粒为基数的蛋白质绝对含量 (以下简称单粒蛋白质含量)的变化如图 2 所示。 


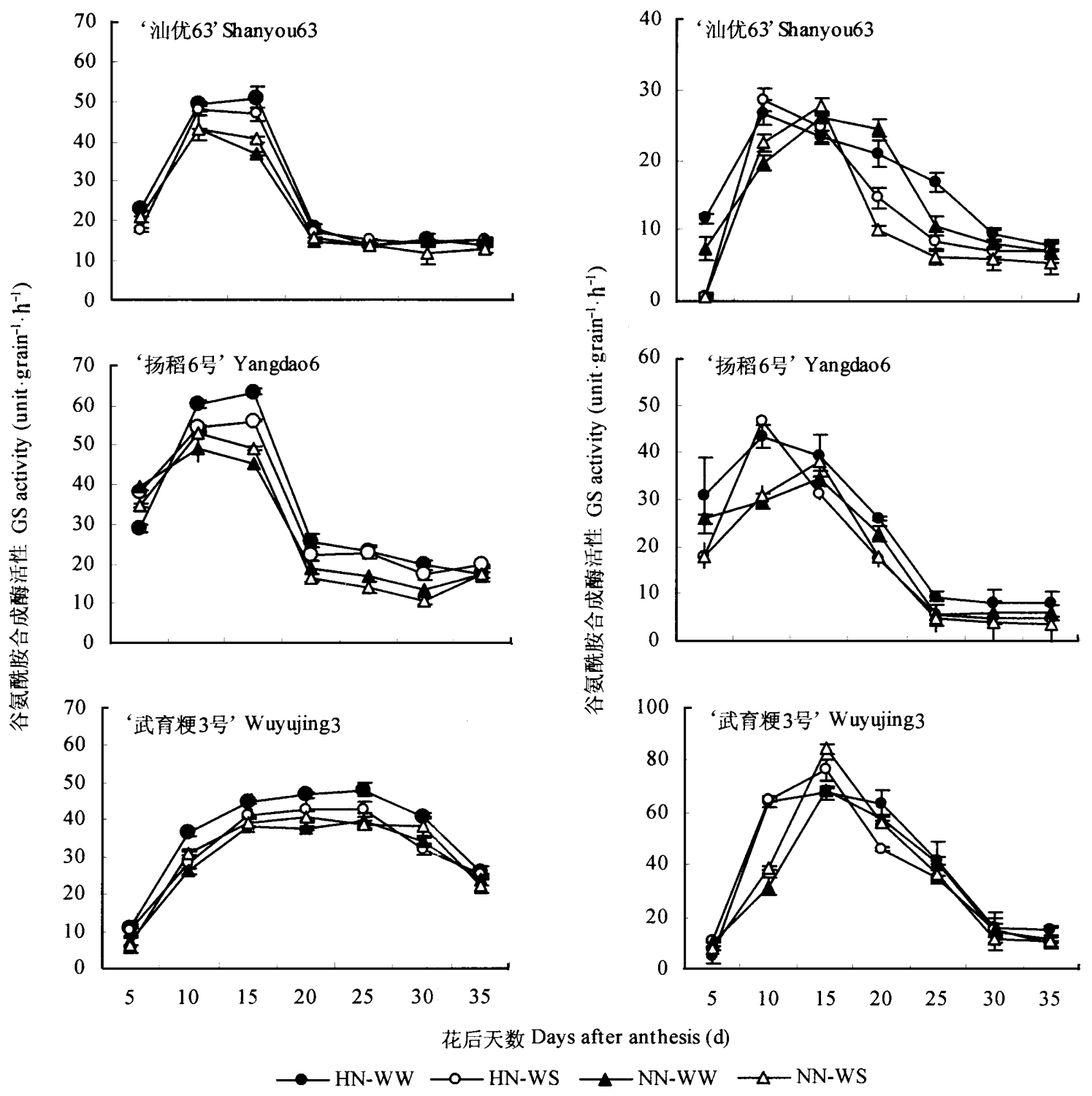

图 1 不同土水势下籽粒中 GS 和 GOGAT 活性的变化

Fig. 1 Changes of activities of GS and GOGAT in the grains

HN-WW : 高氮水层灌溉处理 High nitrogon with well water HN-WS : 高氮水分胁迫处理 High nitrogen with water stress NN-WW : 正常施氮水层 灌溉处理 Normal nitrogen with well water NN-WS : 正常施氮水分胁迫处理 Normal nitrogen with water stress

不同土壤水势下蛋白质含有率的变化趋势 3 个 供试品种(图 2 A , B , C) 基本相似, 呈 V”字型曲线, 开花后 $5 \mathrm{~d}$ 籽粒内蛋白质含有率最高, 然后迅速下 降 到花后 $10 \mathrm{~d}$, 蛋白质含有率下降至最低, 随后蛋 白质含有率又略有上升, 但增加幅度较小, 到花后 $25 \sim 30 \mathrm{~d}$, 蛋白质含有率略有下降。水分胁迫对蛋 白质含有率的影响与供氮水平有着密切的关系,在 正常施氮水平下, 水分胁迫明显提高了花后 $15 \mathrm{~d}$ 至 成熟期蛋白质含有率，而高氮水平下，水分胁迫处理 的蛋白质含有率明显低于水层灌溉。

由图 2(D,E, F) 可以看出: 单粒蛋白质含量实
际上是随着灌浆日数的增加而逐渐增加, 呈 $\mathrm{S}$ ”形增 长, 与米粒生长曲线大体同步(数据未列出)。花后 $5 \sim 20 \mathrm{~d}$, 单粒蛋白质含量增加较快, 其后增加相对 比较平稳。在正常施氮水平下,水分胁迫利于灌浆 前中期(花后 5 15 d) 籽粒内蛋白质的累积, 但随着 水分胁迫时间的延长，单粒蛋白质含量的积累速率 低于水层灌溉，水分胁迫处理的单粒蛋白质含量的 最终积累量低于水层处理; 而在高氮水平下, 整个灌 浆期水分胁迫处理的单粒蛋白质含量要高于水层。 由此可知 结实期提高植株的供氮水平，利于籽粒蛋 白质积累。 


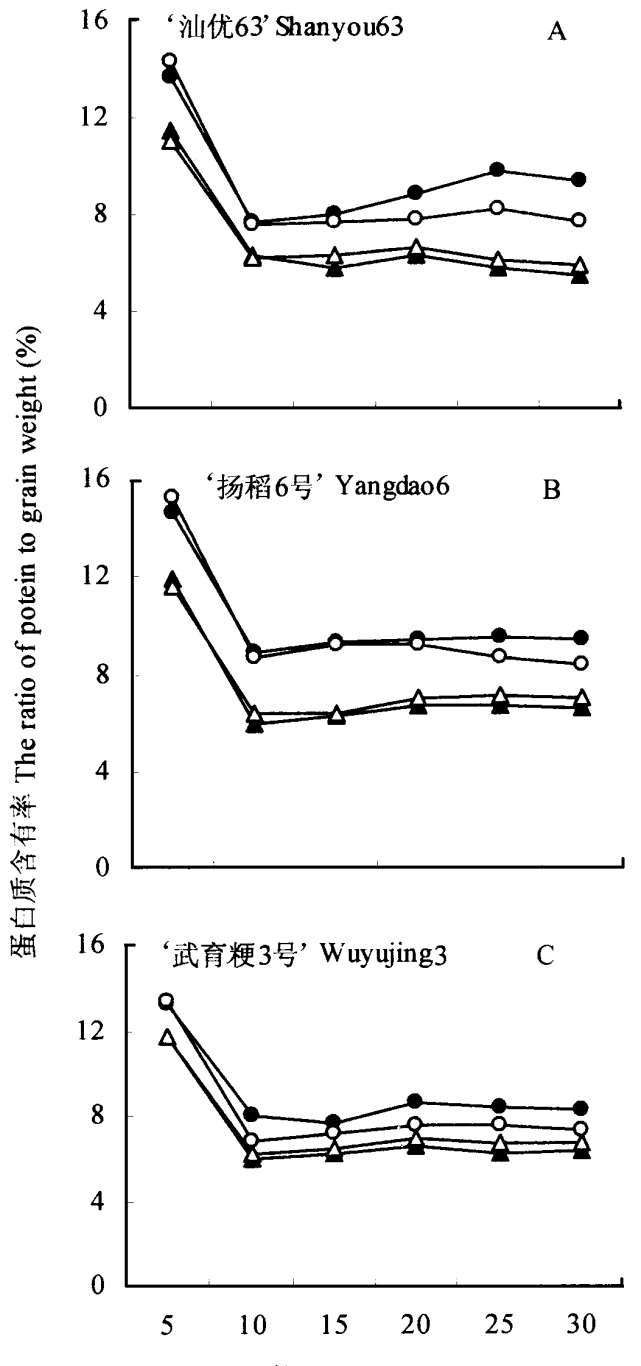

花后天数 Days after anthesis (d)

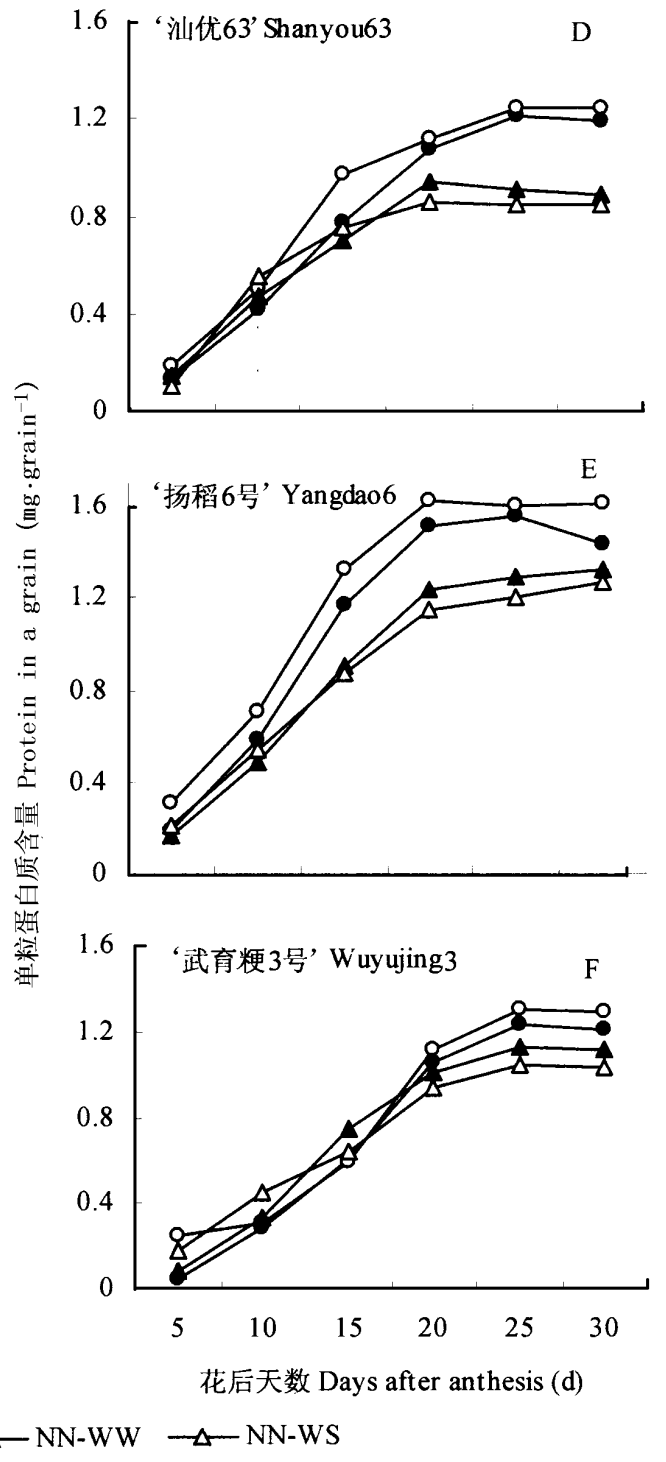

图 2 不同土水势下两种氮肥水平下籽粒中蛋白质含量的变化

Fig.2 Change of protein content of grain under two nitrogen levels and different soil water potentials NN-WW、HN-WS、NN-WW、NN-WS :同图 1 See Fig. 1

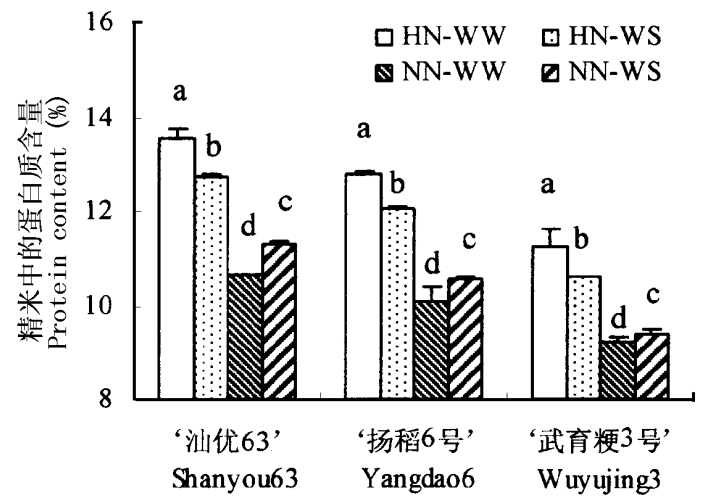

图 3 水分胁迫对两种氮肥水平下精米中粗蛋白含量的影响 Fig.3 Protein contents of rice grain in two nitrogen levels subjected to water stress

NN-WW、HN-WS、NN-WW、NN-WS :同图 1 See Fig. 1

\section{3 水分胁迫对精米中粗蛋白含量的影响}

水分胁迫对两种氮肥水平下精米中粗蛋白含量 的影响各品种表现的趋势基本上一致（图 3)。在正 常施氮水平下, 水分胁迫明显提高了精米中粗蛋白 含量; 而在高氮水平下, 水分胁迫明显降低了精米中 的粗蛋白含量。此外，在同一土壤水势下 结实期施 氮明显提高精米中的蛋白质含量, 而且在水层灌溉 条件下, 米粒中粗蛋白含量提高幅度更大。

\section{4 水分胁迫对籽粒内蛋白质各组分含量的影响}

稻米营养品质好不仅要稻米蛋白质含量高，而 且蛋白质质量要好。本研究结果发现 4 种蛋白质组 分的变化因品种、水分及氮肥处理的不同而不同，水 分胁迫和氮肥施用量不同程度地改变稻米蛋白 4 种 
组分的含量 $($ 表 1), 具体表现为：

1)清蛋白 结实期增施氮肥, 清蛋白含量明显降 低，水分胁迫下清蛋白含量降得更低;而在正常施氮 水平下, 水分胁迫对清蛋白的影响因品种而异“, 汕 优 63' 和 扬稻 6 号' 两品种水分处理间差异不显 著', 武育粳 3 号' NN-WS 处理的清蛋白却明显低于 水层灌溉。

2)球蛋白 水分胁迫对正常施氮水平下 3 品种 籽粒中球蛋白含量无显著影响，但却显著降低高氮 水平下 汕优 $63^{\prime}$ 籽粒中球蛋白。同一水分处理下, 球蛋白含量随着施氮量的增加而显著增加（扬稻 6 号' HN-WS 处理除外), 在低土壤水势下,增施氮肥 对 扬稻 6 号' 精米中球蛋白含量没有明显的影响。

3)醇溶蛋白 :正常施氮水平下, 水分胁迫显著提 高了 汕优 63' 精米中醇溶性蛋白, 而不影响 扬稻 6 号' 和 武育粳 3 号' ; 高氮水平下, 水分胁迫明显降 低了 3 个供试材料精米中醇溶蛋白含量。氮水平对 精米中醇溶蛋白的影响因土壤水势和品种而异, 在 水层灌浆条件下 3 品种表现趋势一致, 高氮水平明 显增加了精米中醇溶性蛋白含量；而在水分胁迫下，
增施氮肥不影响 扬稻 6 号' 和 武育粳 3 号' 精米中 醇溶性蛋白，而汕优 $63^{\prime}$ 却因施氮量的增加而显著 增加。

4)谷蛋白 水分胁迫对谷蛋白影响 3 供试品种 表现趋势基本一致，正常施氮水平下，水分胁迫明显 提高谷蛋白含量, 而高氮水平下谷蛋白含量却显著 降低。在同一种土壤水势下,施氮量多的精米中谷 蛋白含量也高, 只是在水分胁迫下精米中谷蛋白含 量增加的幅度较小。

\section{5 水分胁迫对不同氮肥水平下精米中赖氨酸含} 量的影响

稻米营养品质评价的主要指标，包括稻米蛋白 质数量和质量两个方面, 前者一般指精米(或䊁米) 中粗蛋白含量, 后者以精米(或楉米)中必需氨基酸 来表示。由于赖氨酸为稻米的第一限制氨基酸, 因 此一般以稻米中赖氨酸含量来衡量稻米蛋白质质 量。本试验条件下结实期两种氮肥水平下各品种受 水分胁迫后精米中赖氨酸含量的变化如表 2 所示。

由表 2 可知，水分胁迫显著降低了两种氮肥水 平下 汕优63' 精米中赖氨酸含量, 但却明显提高

表 1 水分胁迫对两种氮肥水平下精米中蛋白质各组份含量的影响 (\%)

Table 1 Effect of water stress on the components of protein of milled rice in two nitrogen level

\begin{tabular}{|c|c|c|c|c|c|}
\hline $\begin{array}{c}\text { 品 种 } \\
\text { Cultivars }\end{array}$ & $\begin{array}{c}\text { 处理 } \\
\text { Treatments }\end{array}$ & $\begin{array}{l}\text { 清蛋白 } \\
\text { Albumin }\end{array}$ & $\begin{array}{l}\text { 球蛋白 } \\
\text { Globulin }\end{array}$ & $\begin{array}{c}\text { 醇溶蛋白 } \\
\text { Prolamine }\end{array}$ & $\begin{array}{l}\text { 谷蛋白 } \\
\text { Glutelin }\end{array}$ \\
\hline \multirow{4}{*}{$\begin{array}{c}\text { 汕优 63’ } \\
\text { Shanyou63 }\end{array}$} & HN-WW & $0.47^{\mathrm{b}}$ & $0.73^{\mathrm{a}}$ & $1.22^{\mathrm{a}}$ & $11.13^{\mathrm{a}}$ \\
\hline & HN-WS & $0.40^{\mathrm{b}}$ & $0.60^{\mathrm{b}}$ & $1.00^{\mathrm{b}}$ & $10.75^{\mathrm{b}}$ \\
\hline & NN-WW & $0.60^{\mathrm{a}}$ & $0.55^{\mathrm{b}}$ & $0.42^{\mathrm{d}}$ & $9.73^{\mathrm{d}}$ \\
\hline & NN-WS & $0.57^{\mathrm{a}}$ & $0.50^{\mathrm{b}}$ & $0.70^{c}$ & $9.88^{c}$ \\
\hline \multirow{4}{*}{$\begin{array}{c}\text { ‘扬稻 } 6 \text { 号’ } \\
\text { Yangdao6 }\end{array}$} & HN-WW & $0.51^{\mathrm{b}}$ & $0.41^{\mathrm{a}}$ & $0.90^{\mathrm{a}}$ & $10.98^{\mathrm{a}}$ \\
\hline & HN-WS & $0.43^{b}$ & $0.38^{\mathrm{ab}}$ & $0.74^{\mathrm{b}}$ & $10.50^{\mathrm{b}}$ \\
\hline & NN-WW & $0.62^{\mathrm{a}}$ & $0.34^{\mathrm{b}}$ & $0.64^{\mathrm{b}}$ & $8.50^{\mathrm{d}}$ \\
\hline & NN-WS & $0.61^{\mathrm{a}}$ & $0.36^{\mathrm{b}}$ & $0.70^{\mathrm{b}}$ & $8.80^{\mathrm{c}}$ \\
\hline \multirow{4}{*}{$\begin{array}{c}\text { ‘武育粳 } 3 \text { 号' } \\
\text { Wuyujing3 }\end{array}$} & HN-WW & $0.30^{\mathrm{c}}$ & $0.84^{\mathrm{a}}$ & $0.88^{\mathrm{a}}$ & $9.23^{\mathrm{a}}$ \\
\hline & HN-WS & $0.26^{\mathrm{c}}$ & $0.78^{\mathrm{a}}$ & $0.70^{\mathrm{b}}$ & $8.86^{\mathrm{b}}$ \\
\hline & NN-WW & $0.61^{\mathrm{a}}$ & $0.61^{\mathrm{b}}$ & $0.61^{\mathrm{c}}$ & $7.42^{\mathrm{d}}$ \\
\hline & NN-WS & $0.40^{\mathrm{b}}$ & $0.68^{\mathrm{b}}$ & $0.64^{\mathrm{bc}}$ & $7.68^{\mathrm{c}}$ \\
\hline
\end{tabular}

$\mathrm{a} 、 \mathrm{~b} 、 \mathrm{c}$ 表示同一品种内不同处理间在 0.05 水平上进行 $P L S D$ 多重比较 $\mathrm{a}, \mathrm{b}, \mathrm{c}$ mean that the comparison was in the same cultivar under 0.05 level HN-WW、HN-WS、NN-WW、NN-WS :同图 1 See Fig. 1

表 2 水分胁迫对两种氮肥水平下精米中赖氨酸含量的影响 $\left(\mathbf{m g ~ m g}^{-\mathbf{1}}\right)$

Table 2 Effect of water stress on the lysine content in two nitrogen levels $\left(\mathrm{mg} \mathrm{mg}^{-1}\right)$

\begin{tabular}{cccc}
\hline 处 理 Treatments & '汕优 63’ Shanyou63 & '扬稻 6 号’ Yangdao6 & '武育粳 3 号’ Wuyujing3 \\
\hline HN-WW & $7.58 \pm 0.281$ & $5.58 \pm 0.065$ & $5.18 \pm 0.169$ \\
HN-WS & $7.04 \pm 0.523$ & $6.37 \pm 0.101$ & $4.93 \pm 0.135$ \\
NN-WW & $6.27 \pm 0.065$ & $4.64 \pm 0.299$ & $4.15 \pm 0.001$ \\
NN-WS & $5.69 \pm 0.055$ & $4.76 \pm 0.479$ & $4.32 \pm 0.135$ \\
\hline
\end{tabular}


扬稻 6 号”赖氨酸含量。而水分胁迫下 武育粳 3 号' 精米中赖氨酸含量变化因施氮水平的不同而不 同, 正常施氮水平下赖氨酸含量略有升高; 而高氮水 平下赖氨酸含量明显降低,此外,由表 2 还可以看 出, 在相同的土壤水势下, 结实期增施氮肥利于提高 精米中赖氨酸含量。

\section{3 讨 论}

稻米蛋白质是一个遗传力较低的品质指标, 稻 米蛋白质含量的遗传力只有 $25 \% \sim 50 \%$ 或更低, 而 环境条件对蛋白质含量影响更大( Takeda，1979)。 有关土壤水分与水稻籽粒中蛋白质关系的研究主要 集中在最终籽粒蛋白质含量上 (黄发松等, 1998), 很少报道籽粒内蛋白代谢及其积累的变化。本研究 结果表明 始穗期施高氮利于籽粒氮代谢与蛋白质 积累，而水分胁迫效应因追氮水平不同而不同，究其 原因可能与水分胁迫后水稻植株体内碳氮代谢发生 了改变有关。正常施氮水平下, 灌浆过程中水分胁 迫处理的 GS 和 GOGAT 活性在花后 10 20 d 略有 增加 籽粒自身合成含氮化合物的能力略有升高, 但 由于茎鞘和叶片中转移到籽粒中的含氮化合物又相 应减少(王维，2003) ,籽粒中氮素积累量相应减少， 从而导致单粒蛋白质含量降低; 另一方面, 水分胁迫 更加削弱了正常施氮水平下籽粒中淀粉的合成 (Yang et al . , 2003) 转移到籽粒中碳水化合物的量 相应地减少得更多 (籽粒重明显降低), 导致以干重 为基数的蛋白质含有率在水分胁迫下仍要高于水层 灌溉处理。而高氮水平下，尽管水分胁迫处理的 GS 和 GOGAT 活性在花后 10 20 d 要低于水层灌溉处 理, 籽粒合成含氮化合物的能力降低, 但由于植株含 氮水平仍较高(数据未列出), 提高了叶片与籽粒间 的氮素位势差, 水分胁迫高氮水平下促进了水稻植 株茎鞘和叶片中的氮向籽粒的运转, 增强了籽粒蛋 白质形成的氮源, 促进了籽粒中蛋白质的积累, 所以 $\mathrm{HN}-\mathrm{WS}$ 处理的单粒蛋白质含量要高于 HN-WW 处 理。然而,由于 HN-WS 处理籽粒淀粉积累量明显高 于 HN-WW 处理 (Yang et al. ,2003) ,从而造成以单 粒重为基数的 HN-WS 处理蛋白质含有率要低于 HN-WW 处理。

稻米蛋白质含量虽然不高, 但其被人体摄入形 成体蛋白却相对较高, 即稻米的营养价较高, 这主要 由于富含赖氨酸的谷蛋白占到蛋白质总量的 $80 \%$ 左右 (Matsuzaki et al. , 1973)。丁艳锋等 (2003) 研究 发现穗肥的施用使稻米醇溶蛋白和谷蛋白含量均有
较明显的提高, 本研究也证实了这一点, 始穗期增施 氮肥利于醇溶蛋白和谷蛋白的提高。本文结果表 明, 水分胁迫对水稻籽粒 4 种蛋白质组分和赖氨酸 含量的影响因品种和追氮水平的不同而不同, 水分 胁迫显著降低高氮水平下籽粒内醇溶蛋白和谷蛋白 含量以及赖氨酸含量 ( 扬稻 6 号” 除外) , 而同一土 壤水分条件下增施氮肥却增加醇溶蛋白和谷蛋白 以及总的粗蛋白含量。因此, 本研究推测结实期施 氮过高的情况下, 可通过适度的土壤水分胁迫措施 来调节蛋白质的积累，从而达到既提高稻米的营养 品质, 又不影响米饭的食味。然而, 这一推测结果还 有待今后进一步研究和验证。

\section{参 考 文 献}

Chen YQ (陈毓荃) (1995). Research Techniqe of Biochemical Technology (生物化学研究技术). China Agriculture Press, Beijing, 196 - 197.

Ding YF (丁艳锋), Zhao CH (赵长华), Wang QS (王强盛), Wang SH (王绍华), Huang PS (黄丕生) (2003). Effect of application time of panicle fertileizer on accumulation of endosperm protein in rice kernels. Acta Agronomica Sinica (作物 学报), 29, 606-609 (in Chinese with English abstract)

Dunn TS, Fitzgerald MA, Batten GD (2000). A panicle culture system to manipulate protein in rice grain. In: Wootton M, Batey IL, Wrigley CW eds. Proceeding of 11 th Cereals and Bread Congress, Rice Satellite Symposium. Royal Australian Chemical Institute, Queensland, Australia, 15.

Evers T, Millart S (2002). Cereal grain structure and development: some implications for quality. Journal of Cereal Science, 36, $261-284$.

Huang FS (黄发松), Sun ZX (孙宗修), Hu PS (胡培松), Tang SQ (唐绍清) (1998). Present situations and prospects for the research on rice grain quality for ming. Chinese Journal of Rice Science (中国水稻科学) , 12,172-176. (in Chinese with English abstract)

Lawlor DW (2002). Carbon and nitrogen assimilation in relation to yield, mechanisms are the key to understanding production systems. Journal of Experimental Botany, 53,773- 787.

Li HS (李合生) (1999). Experimental Principle and Technique for Plant Physiology and Biochemistry (植物生理生化实验原理 和技术). Higher Education Press, Beijing, 250 - 252. (in Chinese)

Lu LS (卢良恕) (1990). The food demand and countermeasure of China in 2000. Chinese Agricultural Science Bulletin (中国农学 通报), 6(1), 1-5. (in Chinese with English abstract)

Martin M, Fitzgerald MA (2002). Proteins in rice grains influence 
cooking properties. Journal of Cereal Science, 36, 285 - 294. Matsuzaki A, Matsushima S, Tomita T (1973). Effects of the nitrogen top-dressing at the full heading stage on kernel qualities. Proceedings of the Crop Science Society of Japan, 42, 54-62.

Okadome H, Kurihara M, Kusuda O, Toyoshima H, Kim J, Shinotsubo K, Matsuda T, Ohtubo K (1999). Multiple measurements of physical properties of cooked rice grains with different nitrogenous fertileizers. Japanese Journal of Crop Science, 68, $211-216$.

Takeda S (1979) . Researches on the protein content of rice. Proceedings of the Crop Science Society of Japan, 48, 517 - 524.

Wang W (王维) (2003). Soil Drying in Regulation to the Remobilization of Carbon and Nitrogen Reserves During Grain-Filling Period of Wheat and Rice and Its Physiological Mechanism (适度土
壤干旱对稻麦碳氮营养运转的调节作用及其机理). $\mathrm{PhD}$ dissertation, Yangzhou University, Yangzhou, 115 - 131. (in Chinese with English abstract)

Yang J, Zhang J, Wang Z, Zhu Q, Liu L (2003) . Activities of enzymes involved in sucrose-to-starch metabolism in rice grains subjected to water stress during filling. Field Crop Research, 81, $69-81$.

Zou Q (刍琦) (2000). Experiment Instruction of Plant Physiology (植物生理学实验指导). China Agriculture Press, Beijing, 122 - 123. (in Chinese)

Zhu ZW (朱智伟), Yang W (杨炜), Lin RH (林榕辉) (1991). Nutrient value of rice protein on different rice types. Chinese Journal of Rice Science (中国水稻科学), 5, 157 162. (in Chinese with English abstract) 